\title{
An Evaluation Method of Comprehensive Product Quality for Customer Satisfaction Based on Intuitionistic Fuzzy Number
}

\author{
Wei Xu (D), Yinyun Yu $(\mathbb{D}$, and Qingshan Zhang \\ School of Management, Shenyang University of Technology, No. 111, Shenliao West Road, Economic \& Technological Development Zone, \\ Shenyang 110870, China
}

Correspondence should be addressed to Yinyun Yu; 3035905183@qq.com

Received 18 October 2017; Revised 1 January 2018; Accepted 24 January 2018; Published 25 February 2018

Academic Editor: Silvia Romanelli

Copyright (C) 2018 Wei Xu et al. This is an open access article distributed under the Creative Commons Attribution License, which permits unrestricted use, distribution, and reproduction in any medium, provided the original work is properly cited.

How to maximize customer satisfaction is an important research topic in the service quality evaluation. This paper proposes an evaluation method of comprehensive product quality for customer satisfaction based on the intuitionistic fuzzy number. In this method, we design a questionnaire and investigate the customer's language evaluation information of product quality evaluation, including product expectations and product perception at first. And then, the product quality evaluation model is obtained by Delphi method; that is, the first-level evaluation indexes and the second-level evaluation indexes are obtained and the weight vector of each evaluation index is determined. Next, language evaluation information translates into corresponding fuzzy numbers using intuitionistic fuzzy numbers. Therefore, the results of the product quality evaluation of the production system are obtained using the weighted mean method. Finally, an example is used to illustrate the feasibility and effectiveness of the proposed method.

\section{Introduction}

According to the concept of modern marketing, [1] a product can provide customers with a certain value, including objects and processes. Consequently, products can be decomposed into tangible goods and intangible services. Customer's evaluation of product quality is usually based on the gap between product perception and product expectation. Providing highquality service products for service-oriented enterprises is to better hold market share and gain greater profits $[2,3]$. In recent years, the product quality evaluation has been focused on industry and manufacture. Through the product quality evaluation results, it is beneficial for the industry and manufacture enterprises to better control the weak links in the existing product quality system and provide a reference for improving the product quality [4]. Product quality evaluation will provide an important basis for product quality improvement.

The issue of product quality evaluation has received considerable attention from researchers and practitioners during the past three decades. In the extant literature there are a number of studies that deal product quality evaluation into two groups: one is the SERVPERF model proposed by
Cronin and Taylor [5]; another is SERVQUAL (the quality evaluation gaps model PZB gap model), a well-known measure, proposed by Parasuraman et al. [6]. The existing literature methods mainly focus on the important analysis of product design, product optimization, and product quality evaluation. However, studies on product quality evaluation based on fuzzy environment are very few.

Moreover, product quality evaluation is a combination of various attributes; it contains not only objective attributes but also subjective attributes, many of which are intangible and difficult to measure with numerical accuracy and are fuzzy information [7]. For example, the use of "good," "medium," and "bad" language evaluation can be better expressed by the perception of customers for the evaluation of machine tool equipment. This paper proposes a novel method for customer satisfaction product quality evaluation under fuzzy environment. The remaining section of the paper is organized as follows: Section 2 reviews some of the existing research results of product quality evaluation. Section 3 introduces the research problems and some variables in the design of this proposition. Section 4 proposes a novel method for evaluating the service quality under fuzzy environment. An illustrative example is given to demonstrate the use of the 
proposed method in Section 5. Finally, the conclusion of this paper on the original contributions and suggested future work are drawn.

\section{Literature Review}

Customer satisfaction is the standard to measure the feasibility and quality of service products. After service is provided, a positive or negative reaction will emerge from customers getting that service [8]. Therefore, good customer satisfaction can improve customer loyalty and profitability, return on investment and guarantee the business success in today's competitive world. At the beginning of the 1980s, Grönroos [9] introduces the concept of product quality to the marketing field and puts forward the concept of product quality perception; that is, the customer evaluation of product quality is defined as the gap between the product expectation and the product perception (when the product perception is lower than the product expectation, product quality perception by the customer is poor).

Here are often some attributes that are difficult to quantify with a single value in the product quality evaluation. Compared with the traditional scoring method, the linguistic information evaluation method is more suitable to express the customer's perception. At the same time, this method can fully reflect the problems existing in the product quality system $[5,9]$. In recent years, some scholars have made some studies on language evaluation of the product quality $[5,10-14]$. Because the language evaluation has certain characteristics of fuzziness and hesitancy, when customers in evaluation often show some fuzzy evaluation results, such as "at least very good" or "more than medium," and "between good and very good," this information is known as fuzzy linguistic information [11-14]. Hesitant fuzzy linguistic term sets (HFLTS) are suitable for customers to express their hesitant evaluation information [15-19]. Wu et al. [20] proposed a quality function deployment based on hesitant fuzzy integrated. The method used quality function deployment (QFD) and Vlsekriterijumska Optimizacija I Kompromisno Resenje (VIKOR) method to analyze the interrelationships among customer requirements (CRs) and determine their weight, under hesitant fuzzy environment. Wang et al. [21] used the dual hesitant fuzzy information to evaluate the mechanical product design quality based on multiple attributes. Wang et al. proposed a novel approach for product quality evaluation; to improve customer satisfaction, the method integrates quality function development (QFD), fuzzy extended analytic hierarchy process (FEAHP), and multisegment goal programming (MSGP) [14].

From the existing literature, it is pointed out that the quantification of customer's language information mostly appears as a single value, but little is known about the research results of quantifying the interval. Based on the existing research, this paper gives a quality evaluation method considering customer evaluation interval and replaces the single value with interval method, which can effectively reduce the loss of evaluation information. According to the above review, this paper proposes a novel approach for product quality evaluation under fuzzy environment.

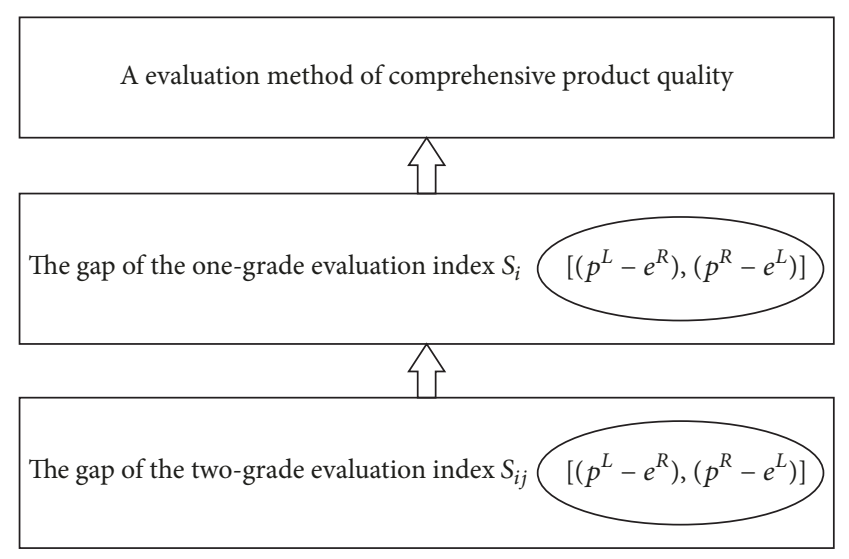

FIgURE 1: Product quality evaluation model.

\section{Sign Interpretation and Problem Description}

Product quality evaluation is usually based on customer's product expectation and product perception. If the products provided by enterprises can meet the customer lowest needs, the customer will be satisfied with the product quality. PZB product quality evaluation model proposed by Parasuraman et al. [6] in 1985 is the most widely used customer-perception product quality evaluation model. This paper proposes a novel approach for product quality evaluation based on $\mathrm{PZB}$ product quality evaluation model, customer language evaluation, as shown in Figure 1.

Definition 1. $S=\left\{S_{1}, S_{2}, \ldots, S_{n}\right\}$ denotes a collection of the first-level evaluation indexes, where $S_{i}$ denotes the $i$ th product quality evaluation index, $i=1,2, \ldots, n$.

Definition 2. $S_{i}=\left\{S_{i 1}, S_{i 2}, \ldots, S_{i m}\right\}$ denotes a collection of the second-level evaluation indexes contained in the $i$ th product quality evaluation index, where $S_{i j}$ denotes the $j$ th secondlevel evaluation index contained in the first-level evaluation index $S_{i}, i=1,2, \ldots, n, j=1,2, \ldots, m$.

Definition 3. $R=\left\{r_{1}, r_{2}, \ldots, r_{n}\right\}$ denotes a collection of weight vectors of the first-level evaluation indexes, where $r_{i}$ denotes the weight vector of the first-level evaluation index $S_{i}, \sum_{i=1}^{n} r_{i}=1, i=1,2, \ldots, n$.

Definition 4. $R_{i}=\left\{r_{i 1}, r_{i 2}, \ldots, r_{i m}\right\}$ denotes a collection of weight vectors of the second-level evaluation index, where $r_{i j}$ denotes the weight vector of the second-level evaluation index $S_{i j}, \sum_{j=1}^{m} r_{i j}=1, i=1,2, \ldots, n, j=1,2, \ldots, m$.

Definition 5. $C=\left\{C_{1}, C_{2}, \ldots, C_{q}\right\}$ denotes a collection of experts participating in product quality evaluation, where $C_{l}$ denotes the first expert participating in the product quality evaluation. We usually employ a number of experts with profound professional knowledge and experience to ensure that we can obtain objective and reasonable judgment of the importance of each index to ensure that the weight vector of each index is objective and reasonable, $l=1,2, \ldots, q$. 
Definition 6. $a^{l}=\left(a_{1}^{l}, a_{2}^{l}, \ldots, a_{n}^{l}\right)$ denotes the weight score value of the first-level evaluation indexes given by an expert $C_{l}$, where $a_{i}^{l}$ denotes the weight score value of the first-level evaluation index $S_{i}$ given by an expert $C_{l}, i=1,2, \ldots, n$.

Definition 7. $a_{i}^{l}=\left(a_{i 1}^{l}, a_{i 2}^{l}, \ldots, a_{i m}^{l}\right)$ denotes the weight score value of the second-level evaluation indexes given by expert $C_{l}$, where $a_{i j}^{l}$ denotes the weight score value of the secondlevel evaluation index $S_{i j}$ given by expert $C_{l}, i=1,2, \ldots, n$, $l=1,2, \ldots, q, j=1,2, \ldots, m$.

Definition 8. $K=\left\{K_{1}, K_{2}, \ldots, K_{t}\right\}$ denotes a collection of customers participating in the questionnaire survey of product quality evaluation, where $K_{k}$ denotes the customer $k$ participating in the questionnaire survey, $k=1,2, \ldots, t$.

Definition 9. $P_{i}^{k L}=\left(p_{i 1}^{k L}, p_{i 2}^{k L}, \ldots, p_{i m}^{k L}\right)$ denotes that the customer $K_{k}$ gives the minimum product perception for the second-level evaluation index $S_{i j}$, that is, customer perception of the lower limit, which is an intuitionistic fuzzy number, where $p_{i j}^{k L}$ denotes that the customer $k$ gives the minimum product perception of the second-level evaluation index $S_{i j}$, $i=1,2, \ldots, n, j=1,2, \ldots, m, k=1,2, \ldots, t$.

Definition 10. $P_{i}^{k R}=\left(p_{i 1}^{k R}, p_{i 2}^{k R}, \ldots, p_{i m}^{k R}\right)$ denotes that the customer $K_{k}$ gives the maximum product perception for the second-level evaluation index $S_{i j}$, that is, customer perception of the upper limit, which is an intuitionistic fuzzy number, where $p_{i j}^{k R}$ denotes that the $k$ th customer gives the maximum product perception of the second-level evaluation index $S_{i j}$, $i=1,2, \ldots, n, j=1,2, \ldots, m, k=1,2, \ldots, t$.

Definition 11. $E_{i}^{k L}=\left(e_{i 1}^{k L}, e_{i 2}^{k L}, \ldots, e_{i m}^{k L}\right)$ denotes that the customer $K_{k}$ gives the minimum product expectation for the second-level evaluation index $S_{i j}$, that is, customer expectation of the lower limit, which is an intuitionistic fuzzy number, where $p_{i j}^{k L}$ denotes that the customer $k$ gives the minimum product expectation of the second-level evaluation index $S_{i j}, i=1,2, \ldots, n, j=1,2, \ldots, m, k=1,2, \ldots, t$.

Definition 12. $E_{i}^{k R}=\left(e_{i 1}^{k R}, e_{i 2}^{k R}, \ldots, e_{i m}^{k R}\right)$ denotes that the customer $K_{k}$ gives the maximum product expectation for the second-level evaluation index $S_{i j}$, that is, customer expectation of the upper limit, which is an intuitionistic fuzzy number, where $p_{i j}^{k L}$ denotes that the $k$ th customer gives the maximum product expectation of the second-level evaluation index $S_{i j}, i=1,2, \ldots, n, j=1,2, \ldots, m, k=1,2, \ldots, t$.

The problem concerned in this paper is how to use language phrases to evaluate the product quality, considering the gap between product expectation and product perception. To solve the product quality evaluation problem under fuzzy environment, we proposed a novel method for product quality evaluation based on an intuitionistic fuzzy number which is presented graphically as shown in Figure 2.

Based on the framework for evaluating product quality, the details of the proposed method are presented as follows.

\section{Product Quality Evaluation Method}

In order to effectively improve customer satisfaction with product quality, a customer satisfaction evaluation method for product quality is proposed based on the intuitionistic fuzzy number. The method consists of 3 aspects: the determination of product quality evaluation index and the determination of its weight, the numerical transformation of fuzzy language evaluation, and the calculation of product quality perception value.

4.1. The Determination of Product Quality Evaluation Index. Through customer interview and literature analysis, the quality evaluation index system of a service system is determined.

First of all, according to the existing research results [1115], we were collected, analyzed, and refined product quality evaluation indicators and then formed an alternative set of the evaluation index. Next, some experts use Delphi method to screen the set of alternative indicators. In the end, the interview method was used to interview the target customers to determine the weight of each index.

According to the importance score given by the customer to the first-level evaluation indexes, the relative weight determination method [22] is used to determine the weight of indexes that can be calculated as

$$
r_{i}=\frac{\sum_{l=1}^{q} a_{i}^{l}}{\sum_{i=1}^{n} \sum_{l=1}^{q} a_{i}^{l}}, \quad i=1,2, \ldots, n .
$$

According to the importance score given by the customer to the second-level evaluation index, the weight of it is $r_{i j}$ and that can be calculated using

$$
r_{i j}=\frac{\sum_{l=1}^{q} a_{i j}^{l}}{\sum_{j=1}^{m} \sum_{l=1}^{q} a_{i j}^{l}}, \quad i=1,2, \ldots, n .
$$

\subsection{Numerical Transformation of Fuzzy Language Evaluation}

4.2.1. Intuitionistic Fuzzy Number. In terms of intuitionistic fuzzy number compared with the traditional fuzzy numbers which consider the membership degree and the nonmembership degree of evaluation language, it can express a more comprehensive expression of customer satisfaction for product quality, so it occupied a certain advantage in the fuzzy data analysis [18].

The intuitionistic fuzzy set was mentioned by Bulgarian scholar Atanassov in 1999 [18] and is an extension of the fuzzy set theory proposed by Zadeh [19]. It can be expressed by

$$
\begin{aligned}
A & =\left\{\left(x, u_{A}(x), v_{A}(x)\right) \mid x, u_{A}(x) \in[0,1], v_{A}(x)\right. \\
& \left.\in[0,1], 0 \leq u_{A}(x)+v_{A}(x) \leq 1\right\}
\end{aligned}
$$

where $A$ denotes an intuitionistic fuzzy set; $u_{A}(x)$ and $v_{A}(x)$ denote the membership degree and the nonmembership degree of the intuitionistic fuzzy set $A$. Let $\pi_{A}(x)$ denote the hesitancy degree of the intuitionistic fuzzy set $A, \pi_{A}(x)=1-$ $u_{A}(x)-v_{A}(x)$. Here, $u_{A}(x), v_{A}(x)$, and $\pi_{A}(x)$, respectively, denote the degree of affirmation, negation, and neutrality 


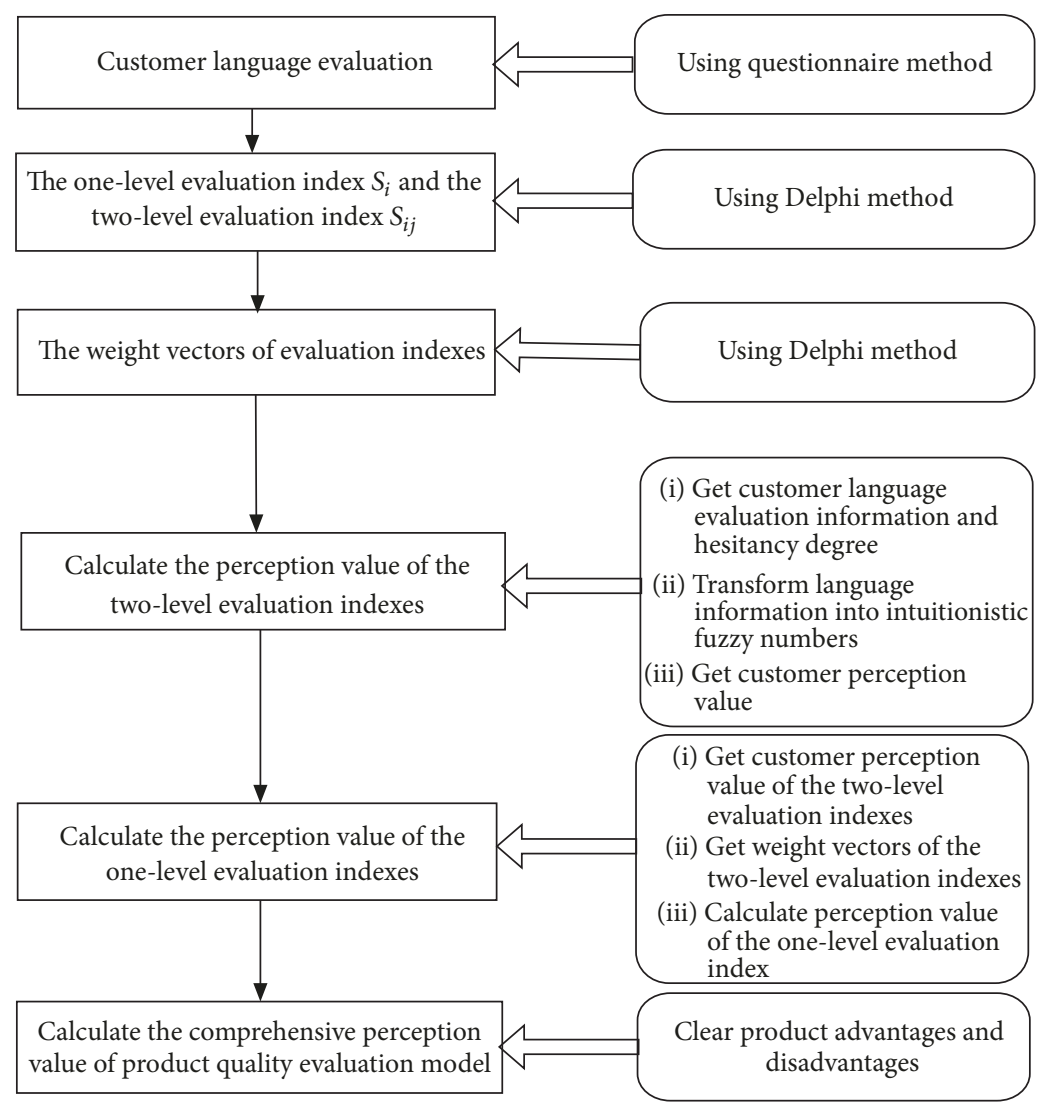

FIGURE 2: The framework of the proposed method.

of object $x$ belonging to the intuitionistic fuzzy set $A$. For example, a intuitionistic fuzzy set $A=\{(x, 0.5,0.3)$ | $x \in X\}$, then its membership degree $u_{A}(x)=0.5$ and its nonmembership degree $v_{A}(x)=0.3$, and the hesitancy degree $\pi_{A}(x)=0.2$ of it; that is, objective $x$ belongs to $A$ degree that is 0.5 and does not belong to the degree of $A$ of 0.3 and the degree of neutrality of 0.2 .

4.2.2. Determination of Satisfaction. In the evaluation of manufacturing products, many indicators using language description can better express customer perception of product quality satisfaction.

For example, the sensitivity of operation, after-sales service satisfaction, and other vague language "good," "medium," "bad," and so on to express that can better reflect the customer satisfaction perception. Therefore, this paper requires the target customer to give the evaluation information in the form of language phrase, then, using the intuitionistic fuzzy number to transform the fuzzy language of uncertainty into the corresponding fuzzy number.

In this paper, the fuzzy language evaluation information is transformed into an intuitionistic fuzzy number by the method proposed by Zhang et al. [23].

It is assumed that the membership degree is $u_{A}(x)$ and the nonmembership degree is $v_{A}(x)$ of the fuzzy language evaluation. Then, collect the degree of hesitancy and language evaluation information given by the target customers and transform it into an intuitionistic fuzzy number $\left[u_{A}(x)-\alpha \times\right.$ $\left.\pi_{A}(x), v_{A}(x)-\beta \times \pi_{A}(x)\right], \alpha+\beta=1$, where $\alpha$ and $\beta$ represent the uncertain degree of higher and lower level. For example, VP (0.2) said customers are not satisfied with the product index and the hesitancy degree of 0.2 ; according to Table 1 , the intuitionistic fuzzy number obtained is $[0.1,0.3]$. Let $\left(e^{L}, e^{R}\right)$ denote the fuzzy interval of customer satisfaction evaluation for product quality.

4.3. Calculation of Product Perception Value. In life, there is a certain deviation between customer's expectation level of product and product perception (customer satisfaction), which is called product perception value [24]. Because the product perception of customers is in the form of interval, so the product quality perception value is also an interval. Note $\left[h_{i j}^{k L}, h_{i j}^{k R}\right]$ for the customer $G_{k}$ for the second-level evaluation of product perception value range, where $h_{i j}^{k L}$ denotes the product perception appropriate value; $h_{i j}^{k R}$ denotes the product perception advantage value. They can be calculated by

$$
\begin{aligned}
h_{i j}^{k L}=p_{i j}^{k L}-e_{i j}^{k R}, & \\
& \quad i=1,2, \ldots, n, j=1,2, \ldots, m, k=1,2, \ldots, t, \\
h_{i j}^{k R}=p_{i j}^{k R}-e_{i j}^{k L}, & \\
\quad & \quad=1,2, \ldots, n, j=1,2, \ldots, m, k=1,2, \ldots, t .
\end{aligned}
$$


TABLE 1: The intuitionistic fuzzy numbers corresponding to the language information.

\begin{tabular}{lcr}
\hline Language information & Intuitionistic fuzzy numbers & $\alpha, \beta$ value \\
\hline Extremely poor (EP) & $0.1-\alpha \times \pi, 0.1+\beta \times \pi$ & $\alpha=0, \beta=1$ \\
Very poor (VP) & $0.2-\alpha \times \pi, 0.2+\beta \times \pi$ & $\alpha=0.5, \beta=0.5$ \\
Poor (P) & $0.3-\alpha \times \pi, 0.3+\beta \times \pi$ & $\alpha=0.5, \beta=0.5$ \\
Slightly poor (SP) & $0.4-\alpha \times \pi, 0.4+\beta \times \pi$ & $\alpha=0.5, \beta=0.5$ \\
Middle (M) & $0.5-\alpha \times \pi, 0.5+\beta \times \pi$ & $\alpha=0.5, \beta=0.5$ \\
Slightly good (SG) & $0.6-\alpha \times \pi, 0.6+\beta \times \pi$ & $\alpha=0.5, \beta=0.5$ \\
Good (G) & $0.7-\alpha \times \pi, 0.7+\beta \times \pi$ & $\alpha=0.5, \beta=0.5$ \\
Very good (VG) & $0.8-\alpha \times \pi, 0.8+\beta \times \pi$ & $\alpha=0.5, \beta=0.5$ \\
Extremely good (EG) & $0.9-\alpha \times \pi, 0.9+\beta \times \pi$ & $\alpha=1, \beta=0$ \\
\hline
\end{tabular}

Next, through the survey of target customers to calculate the average value of customer-perception value of the secondlevel evaluation index $\left[\bar{h}_{i j}^{k L}, \bar{h}_{i j}^{k R}\right]$, where $\bar{h}_{i j}^{k L}$ denotes the product perception appropriate average value; $\bar{h}_{i j}^{k R}$ denotes the product perception advantage average value,

$$
\begin{aligned}
& \bar{h}_{i j}^{L}=\frac{1}{T} \sum_{k=1}^{T} h_{i j}^{k L}, \quad i=1,2, \ldots, n, j=1,2, \ldots, m, \\
& \bar{h}_{i j}^{R}=\frac{1}{T} \sum_{k=1}^{T} h_{i j}^{k R}, \quad i=1,2, \ldots, n, j=1,2, \ldots, m .
\end{aligned}
$$

According to (5), we can effectively get the average value of the product perception appropriate and the product perception advantage which the range of value is $(-1,1)$. For facilitation and better study, we can convert the range of values $(-1,1)$ to $(0,1)$ by

$$
\begin{aligned}
& \bar{h}_{i j}^{L^{\prime}}=\frac{\left(\bar{h}_{i j}^{L}+1\right)}{2}, \quad i=1,2, \ldots, n, j=1,2, \ldots, m, \\
& \bar{h}_{i j}^{R^{\prime}}=\frac{\left(\bar{h}_{i j}^{R}+1\right)}{2}, \quad i=1,2, \ldots, n, j=1,2, \ldots, m .
\end{aligned}
$$

Furthermore, according to the average product perception value and the weight vector of the second-level evaluation index, we can calculate the product perception value of the first-level evaluation indexes using (7). Let $\left[v_{i}{ }^{L}, v_{i}{ }^{R}\right]$ be the product perception value of the first-level evaluation index, where $v_{i}^{L}$ denotes the product perception appropriate value of the first-level evaluation index; $v_{i}^{R}$ denotes the product perception advantage value of the first-level evaluation index.

$$
\begin{aligned}
& v_{i}{ }^{L}=\sum_{j=1}^{m} r_{i j} \bar{h}_{i j}^{L^{\prime}}, \quad i=1,2, \ldots, n, \\
& v_{i}^{R}=\sum_{j=1}^{m} r_{i j} \bar{h}_{i j}^{R^{\prime}}, \quad i=1,2, \ldots, n .
\end{aligned}
$$

Finally, the product quality perception value of the current product quality is determined according to the product perception value and the weight vectors of the first-level evaluation indexes, where $v^{L}$ and $v^{R}$ indicate the comprehensive perception appropriate value and the comprehensive perception advantage value of the product quality. They can be expressed as

$$
\begin{aligned}
v^{L} & =\sum_{i=1}^{n} r_{i} v_{i}^{L}, \\
v^{R} & =\sum_{i=1}^{n} r_{i} v_{i}^{R} .
\end{aligned}
$$

\section{Example Analysis}

The good development of the manufacturing industry can effectively improve the sustainable growth ability of a national economy, solve the major livelihood problems, and enhance the global competitiveness. The key to realize the good development of manufacturing industry lies in the construction of the reasonable industrial structure, advanced technical level, friendly enterprise environment and external support, and the creation of a modern industrial system with high-quality employment. Making the advantages and disadvantages of products clear is the key to achieve sustainable development of enterprises. Taking a main engine industrial enterprise in a city as an example and evaluating its product quality system.

At the first, based on the literature [25-28], the evaluation model of enterprise product quality system is constructed, as is shown in Table 2. The evaluation index is composed of 5 first-level evaluation indexes and 14 second-level evaluation indexes.

Secondly, 8 experts were invited to evaluate the evaluation index of the evaluation system using Delphi method. On the basis of experts' evaluation of the importance score, the weight vector of the first-level evaluation index is calculated according to (2)-(3) As $R=(0.19,0.16,0.21,0.26,0.18)$; the weight vectors of second-level evaluation indexes are, respectively, $R_{1}=(0.29,0.19,0.24,0.28) ; R_{2}=(0.34,0.42,0.24)$; $R_{3}=(0.41,0.21,0.38) ; R_{4}=(0.41,0.59) ; R_{5}=(0.52,0.48)$.

Through a questionnaire survey of target customers, we can get the language evaluation of product expectation and product perception of this enterprise, as shown in Tables 3 and 4. 
TABLE 2: Enterprise product quality evaluation indexes and its weight.

\begin{tabular}{|c|c|c|c|}
\hline The first-level evaluation index $S_{i}$ & Weight $R_{i}$ & The second-level evaluation index $S_{i j}$ & Weight $R_{i j}$ \\
\hline \multirow[t]{4}{*}{$S_{1}:$ product elements } & 0.26 & $S_{11}$ : timely after sales maintenance & 0.29 \\
\hline & & $S_{12}:$ delivery within the specified period & 0.19 \\
\hline & & $S_{13}:$ special needs design & 0.24 \\
\hline & & $S_{14}$ : meeting the needs of the market & 0.28 \\
\hline \multirow[t]{3}{*}{$S_{2}$ : basic elements } & 0.19 & $S_{21}$ : timely supply of resources & 0.34 \\
\hline & & $S_{22}:$ perfection of equipment & 0.42 \\
\hline & & $S_{23}$ : employee abundance & 0.24 \\
\hline \multirow[t]{3}{*}{$S_{3}$ : technical elements } & 0.21 & $S_{31}:$ product design capability & 0.41 \\
\hline & & $S_{32}:$ product recovery capability & 0.21 \\
\hline & & $S_{33}$ : employee work skills & 0.38 \\
\hline \multirow[t]{2}{*}{$S_{4}:$ external environmental factors } & 0.16 & $S_{41}:$ proportion of products & 0.41 \\
\hline & & $S_{42}$ : government support & 0.59 \\
\hline \multirow[t]{2}{*}{$S_{5}:$ internal environmental factors } & 0.18 & $S_{51}:$ rationality of management & 0.52 \\
\hline & & $S_{52}:$ employee's work attitude & 0.48 \\
\hline
\end{tabular}

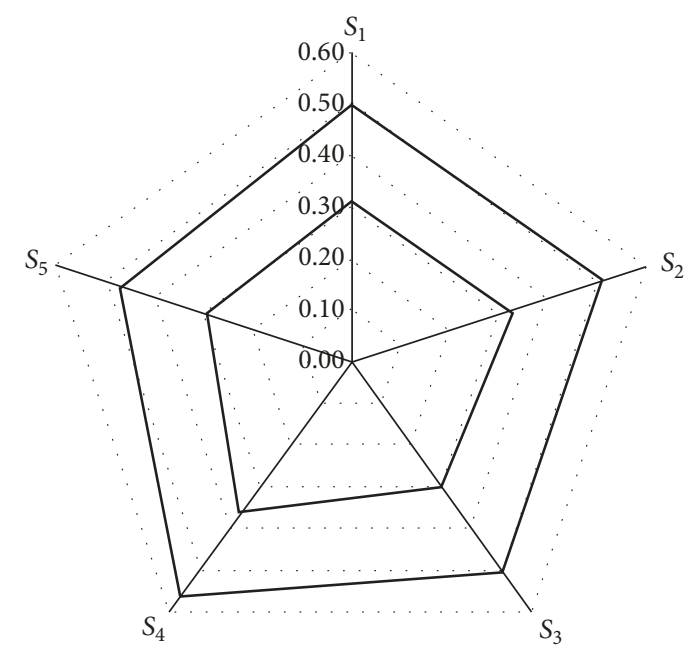

FIgURE 3: The first-level evaluation indexes radar map.

According to Tables 1, 3, and 4, the language evaluation information is converted to intuitionistic fuzzy numbers, as shown in Tables 5 and 6.

It is can be seen that the product perception advantage average value and the product perception appropriate average value can be obtained by (4)-(5), and then we standardize their values using (6), as shown in Table 7.

According to (7), we can obtain the perception appropriate value and perception advantage value of the first-level evaluation indexes and the second-level evaluation indexes, as shown in Table 8.

According to (8), we can calculate that the comprehensive perception appropriate value and the comprehensive perception advantage value are $v^{L}=0.3197$ and $v^{R}=0.7258$.

We use the radar map to visualize the results of the first-level evaluation. Figure 3 shows the perception value of the product in the A City, whose results show that the index of external environmental factors $\left(S_{4}\right)$ is higher than the other evaluation indexes, whether it is the perception appropriate value or the perception advantage value. However, internal environmental factors $\left(S_{5}\right)$ are lower than the other evaluation indexes. According to radar map, managers can determine which dimension index should be improved so as to improve the product quality.

\section{Conclusion}

This paper gives a method of product quality evaluation considering customer satisfaction interval. Firstly, the first-level evaluation indexes and the second-level evaluation indexes are determined by expert Delphi method and Documentary method, and the customers' expectations and perception language evaluation information are obtained through the questionnaire survey. Then, the intuitionistic fuzzy number is used to transform the fuzzy language into the fuzzy number and the perception value of the customer is calculated. On this basis, the comprehensive evaluation system of customer value for products is conducive to better management of existing products to control system improvement. The method presented in this paper has the characteristics of simple calculation, clear thinking, and easy operation. Different from the existing research results, firstly, using language evaluation to replace the traditional evaluation helps customers better products on the expression of expectation and perception; secondly, the language evaluation is transformed into intuitionistic fuzzy number, and, at the same time, using the concept of intuitionistic fuzzy number interval reduces the loss of information and evaluation. Finally, visualization of customer evaluation results is helpful for managers to better understand the weak links of an existing product system and play a certain role in improving product quality and improving customer satisfaction in manufacturing enterprises. 


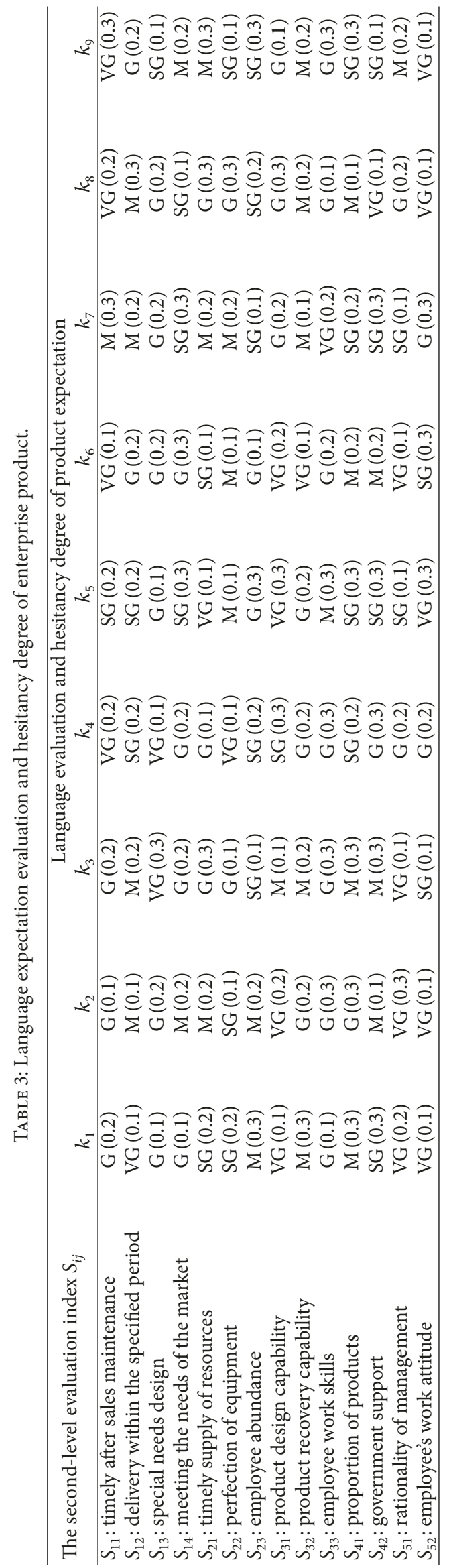




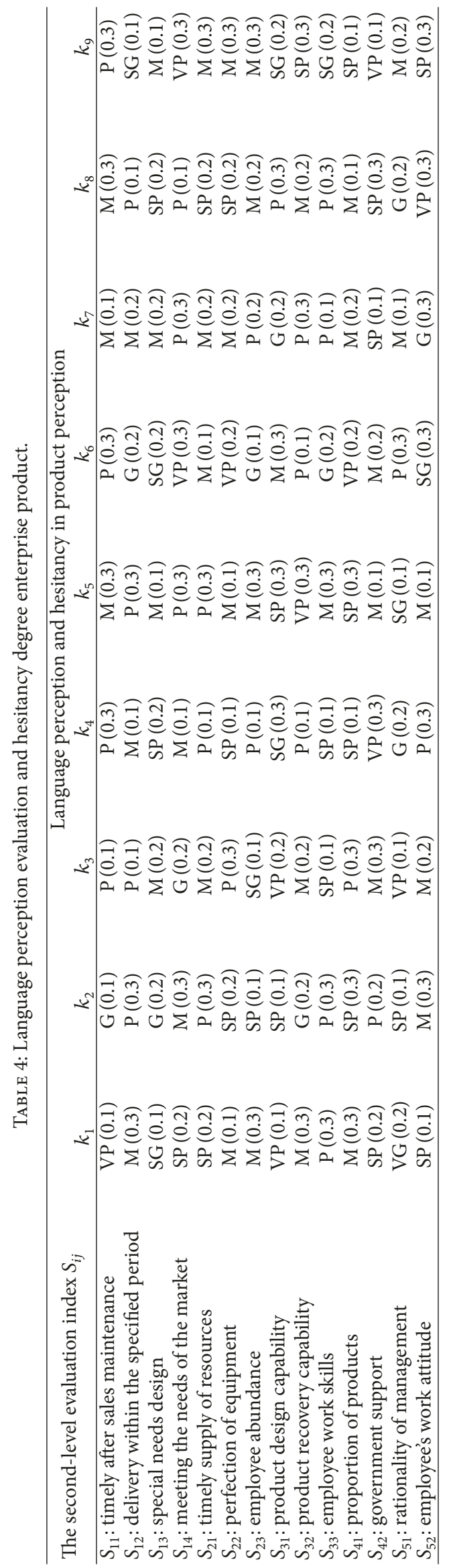




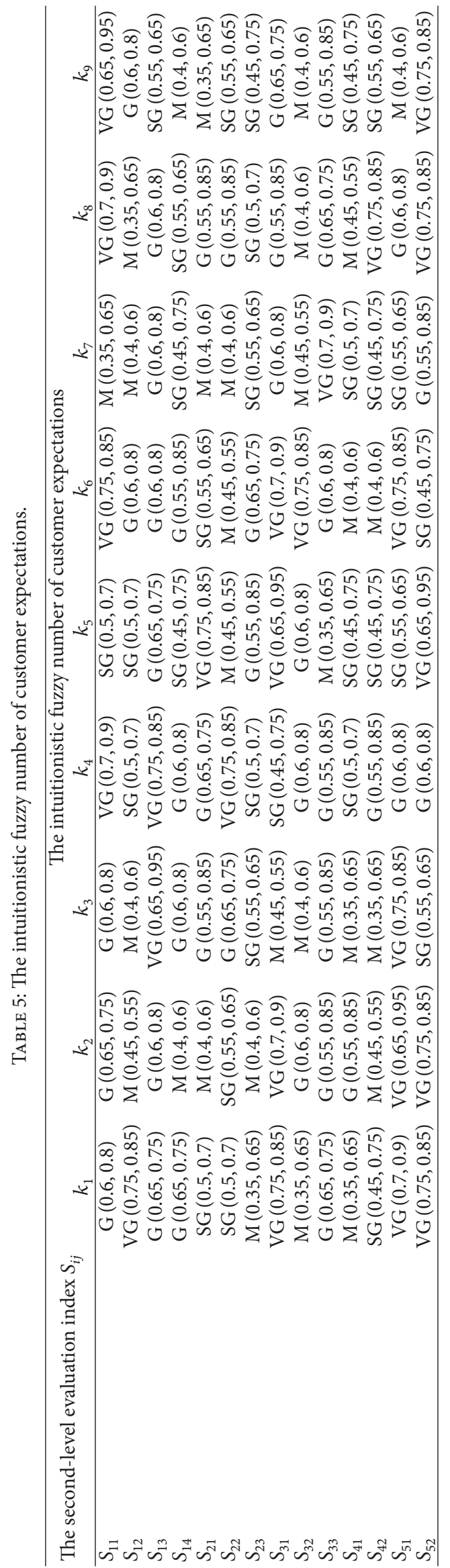




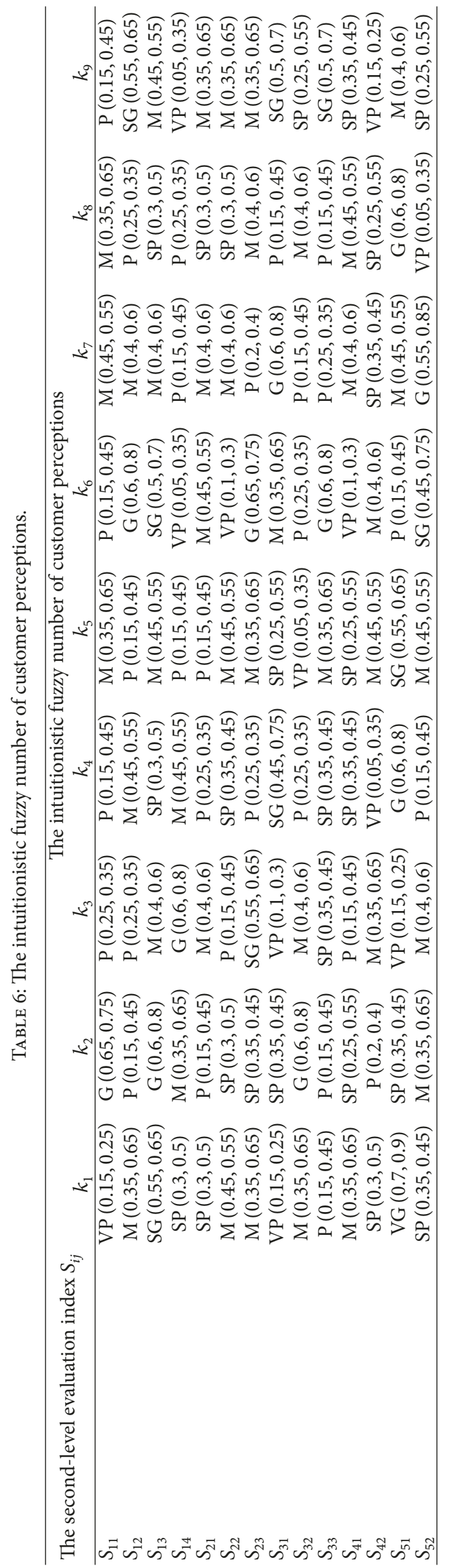


TABLE 7: Standardization of perception advantage value and perception appropriate value.

\begin{tabular}{lcccc}
\hline & $\begin{array}{c}\text { Average perception } \\
\text { appropriate value } \bar{h}_{i j}^{L}\end{array}$ & $\begin{array}{c}\text { Average perception } \\
\text { advantage value } \bar{h}_{i j}^{R}\end{array}$ & $\begin{array}{c}\text { Standardized average perception } \\
\text { appropriate value } \bar{h}_{i j}^{L^{\prime}}\end{array}$ & $\begin{array}{c}\text { Standardized average perception } \\
\text { advantage value } \bar{h}_{i j}^{L^{\prime}}\end{array}$ \\
\hline$S_{11}$ & -0.52 & -0.13 & 0.24 & 0.44 \\
$S_{12}$ & -0.34 & 0.01 & 0.33 & 0.51 \\
$S_{13}$ & -0.31 & 0.02 & 0.34 & 0.51 \\
$S_{14}$ & -0.31 & 0.11 & 0.35 & 0.55 \\
$S_{21}$ & -0.35 & 0.06 & 0.33 & 0.53 \\
$S_{22}$ & -0.34 & -0.01 & 0.33 & 0.50 \\
$S_{23}$ & -0.32 & 0.05 & 0.34 & 0.53 \\
$S_{31}$ & -0.37 & 0.01 & 0.31 & 0.50 \\
$S_{32}$ & -0.30 & 0.10 & 0.35 & 0.55 \\
$S_{33}$ & -0.46 & -0.02 & 0.27 & 0.49 \\
$S_{41}$ & -0.34 & 0.07 & 0.33 & 0.54 \\
$S_{42}$ & -0.22 & 0.16 & 0.39 & 0.58 \\
$S_{51}$ & -0.34 & -0.03 & 0.33 & 0.48 \\
$S_{52}$ & -0.49 & -0.09 & 0.26 & 0.46 \\
\hline
\end{tabular}

TABLE 8: Evaluation index details.

\begin{tabular}{|c|c|c|c|c|c|c|c|}
\hline$S_{i}$ & $R_{i j}$ & $v_{i}^{L}$ & $v_{i}^{R}$ & $S_{i j}$ & $R_{i j}$ & $v_{i j}{ }^{L}$ & $v_{i j}{ }^{R}$ \\
\hline \multirow[t]{4}{*}{$S_{1}$} & 0.26 & 0.3123 & 0.5000 & $S_{11}$ & 0.29 & 0.0701 & 0.1265 \\
\hline & & & & $S_{12}$ & 0.19 & 0.0623 & 0.0961 \\
\hline & & & & $S_{13}$ & 0.24 & 0.0827 & 0.1227 \\
\hline & & & & $S_{14}$ & 0.28 & 0.0972 & 0.1548 \\
\hline \multirow[t]{3}{*}{$S_{2}$} & 0.19 & 0.3313 & 0.5152 & $S_{21}$ & 0.34 & 0.1105 & 0.1804 \\
\hline & & & & $S_{22}$ & 0.42 & 0.1388 & 0.2088 \\
\hline & & & & $S_{23}$ & 0.24 & 0.0820 & 0.1260 \\
\hline \multirow[t]{3}{*}{$S_{3}$} & 0.21 & 0.3056 & 0.5074 & $S_{31}$ & 0.41 & 0.1287 & 0.2061 \\
\hline & & & & $S_{32}$ & 0.21 & 0.0735 & 0.1155 \\
\hline & & & & $S_{33}$ & 0.38 & 0.1034 & 0.1858 \\
\hline \multirow[t]{2}{*}{$S_{4}$} & 0.16 & 0.3666 & 0.5623 & $S_{41}$ & 0.41 & 0.1355 & 0.2198 \\
\hline & & & & $S_{42}$ & 0.59 & 0.2311 & 0.3425 \\
\hline \multirow[t]{2}{*}{$S_{5}$} & 0.18 & 0.2931 & 0.4700 & $S_{51}$ & 0.52 & 0.1704 & 0.2513 \\
\hline & & & & $S_{52}$ & 0.48 & 0.1227 & 0.2187 \\
\hline
\end{tabular}

\section{Discussion}

In this paper, we put forward a method to evaluate the quality of the product: firstly, we introduce fuzzy numbers to ensure the completeness of evaluation information and the correctness of evaluation results; secondly, we use the form of interval to evaluate the product, reducing the loss of customer perceived value. In this paper, a more traditional Delphi method is used to calculate the weight vector of the evaluation index. The Delphi method has great limitations and strict requirements for objective conditions. Because of the limited text, some low influence factors are not taken into consideration when evaluating the product quality. Future research will be concentrated on the analysis of environment influence factors and the weight vector of the evaluation index.

\section{Conflicts of Interest}

The authors declare that they have no conflicts of interest.

\section{Acknowledgments}

This work was financially supported by the Humanities and Social Sciences of Ministry of Education Planning Fund (Grant no. 16YJC630085) in China and the Liaoning Province Department of Education, Projects WGD2016018, WGD2016020, and WGD2016002. Thanks are due to the contribution of Liaoning Key Lab of Equipment Manufacturing Engineering Management, Liaoning Research Base of Equipment Manufacturing Development, Liaoning Key Research Base of Humanities and Social Sciences, Research Center 
of Micromanagement Theory, and Shenyang University of Technology.

\section{References}

[1] H. Huang, "An approach to the performance evaluation of enterprise knowledge management with fuzzy linguistic information," Journal of Convergence Information Technology, vol. 7, no. 5, pp. 106-112, 2012.

[2] H. H. Wu and S. M. Hsieh, "A case study of applying importance-performance analysis in orthopedic department to evaluate service quality," International Journal of Management \& Decision Making, vol. 12, no. 1, pp. 50-68, 2017.

[3] C. G. Şen and H. Baraçli, "Fuzzy quality function deployment based methodology for acquiring enterprise software selection requirements," Expert Systems with Applications, vol. 37, no. 4, pp. 3415-3426, 2010.

[4] M. M. H. Chowdhury and M. A. Quaddus, "A multi-phased QFD based optimization approach to sustainable service design," International Journal of Production Economics, vol. 171, pp. 165-178, 2014.

[5] J. J. Cronin and S. A. Taylor, "Measuring service quality: a reexamination and extension," Journal of Marketing, vol. 56, no. 3, pp. 55-68, 1992.

[6] A. Parasuraman, V. A. Zeithaml, and L. L. Berry, "A conceptual model of service quality and its implications for future research," Journal of Marketing, vol. 49, no. 4, p. 41, 1985.

[7] R. Liu, L. Cui, G. Zeng, H. Wu, and C. Wang, "Applying the fuzzy SERVQUAL method to measure the service quality in certification \& inspection industry," Applied Soft Computing, vol. 26, pp. 508-512, 2014.

[8] E. O. C. Mkpojiogu and N. L. Hashim, "Understanding the relationship between Kano model's customer satisfaction scores and self-stated requirements importance," SpringerPlus, vol. 5, no. 1, article no. 197, pp. 1-22, 2016.

[9] C. Grönroos, "A service quality model and its marketing implications," European Journal of Marketing, vol. 18, no. 4, pp. 36-44, 1984.

[10] S. M. Bhatia and A. K. Sharma, "Fuzzy quality function deployment and software engineering- a literature review," Software Engineering and Technology, vol. 6, no. 6, pp. 396-404, 2014.

[11] K. Sivasamy, C. Arumugam, and S. R. Devadasan, "Advanced models of quality function deployment: a literature review," Quality and Quantity, vol. 50, no. 3, p. 16, 2016.

[12] S. K. Purohit and A. K. Sharma, "Evaluation of programming tools for the development of data mining driven forecasting software tool for quality function deployment," in Proceedings of the 2nd International Conference on Computational Intelligence and Communication Technology, CICT 2016, pp. 134-139, February 2016.

[13] A. Celotto, V. Loia, and S. Senatore, "Fuzzy linguistic approach to quality assessment model for electricity network infrastructure," Information Sciences, vol. 304, pp. 1-15, 2015.

[14] J.-Q. Wang, J.-T. Wu, J. Wang, H.-Y. Zhang, and X.-H. Chen, "Multi-criteria decision-making methods based on the Hausdorff distance of hesitant fuzzy linguistic numbers," Soft Computing, vol. 20, no. 4, pp. 1621-1633, 2015.

[15] A. Parasuraman, L. L. Berry, and V. A. Zeithaml, "Refinement and reassessment of the SERVQUAL scale," Journal of Retailing, vol. 67 , no. 4, pp. 420-450, 1991.
[16] C. Zhang, Z. Fan, and Y. U. Chao, "A Service Quality Evaluation Method Considering the Tolerance Zones of Service Aspirations Provided by Customers," Journal of Industrial Engineering, vol. 19, no. 2, pp. 88-93, 2016.

[17] G. L. Zuo, X. N. Chu, and D. P. Chen, "Product service system optimal selection based on intuitionistic fuzzy information axiom," Computer Integrated Manufacturing Systems, vol. 21, no. 4, pp. 1134-1141, 2015.

[18] K. T. Atanassov, Intuitionistic Fuzzy Sets, Physica-Verlag, NY, USA, 1999.

[19] L. A. Zadeh, "Fuzzy sets," Information and Control, vol. 8, no. 3, pp. 338-353, 1965.

[20] S.-M. Wu, H.-C. Liu, and L.-E. Wang, "Hesitant fuzzy integrated MCDM approach for quality function deployment: a case study in electric vehicle," International Journal of Production Research, vol. 55, no. 15, pp. 4436-4449, 2017.

[21] S.-W. Wang, X.-Q. Ding, and Z.-Z. Ding, "Model for performance evaluation in customs service management with dual hesitant fuzzy information," Journal of Intelligent \& Fuzzy Systems: Applications in Engineering and Technology, vol. 30, no. 4, pp. 2131-2137, 2016.

[22] C.-N. Liao and H.-P. Kao, "An evaluation approach to logistics service using fuzzy theory, quality function development and goal programming," Computers \& Industrial Engineering, vol. 68, no. 1, pp. 54-64, 2014.

[23] D. Zhang, J. Zhang, K.-K. Lai, and Y. Lu, "An novel approach to supplier selection based on vague sets group decision," Expert Systems with Applications, vol. 36, no. 5, pp. 9557-9563, 2009.

[24] J. Ren, X. Zhang, and Y. Zhang, "An approach to software quality assessment with triangular fuzzy linguistic information," International Journal of Digital Content Technology and its Applications, vol. 6, no. 1, pp. 256-262, 2012.

[25] M. Akhundzadeh and B. Shirazi, "Technology selection and evaluation in Iran's pulp and paper industry using 2-filterd fuzzy decision making method," Journal of Cleaner Production, vol. 142, pp. 3028-3043, 2017.

[26] H. Mao, L. Jiao, S. Gao et al., "Surface quality evaluation in meso-scale end-milling operation based on fractal theory and the Taguchi method," The International Journal of Advanced Manufacturing Technology, vol. 91, no. 1-4, pp. 657-665, 2017.

[27] K. Jiang, G. Xu, T. Tao, and L. Liang, "Rolling bearing quality evaluation based on a morphological filter and a Kolmogorov complexity measure," International Journal of Precision Engineering and Manufacturing, vol. 16, no. 3, pp. 459-464, 2015.

[28] H. García, A. Valles, J. Sánchez, S. Noriega, and G. Dominguez, "Statistical equation modeling analysis for industrial projects, designing for critical factors and latent variables: quality, cost, time, and success," The International Journal of Advanced Manufacturing Technology, vol. 88, no. 1-4, pp. 767-779, 2017. 


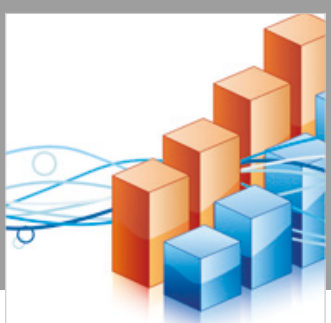

Advances in

Operations Research

\section{-n-m}
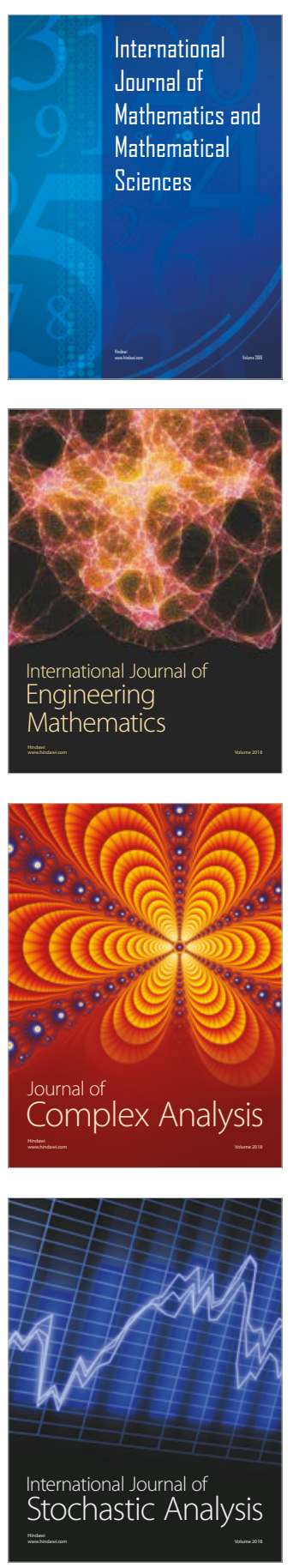
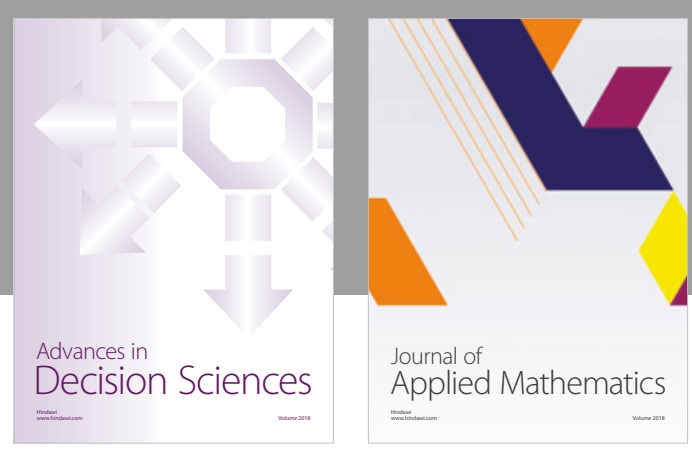

Journal of

Applied Mathematics
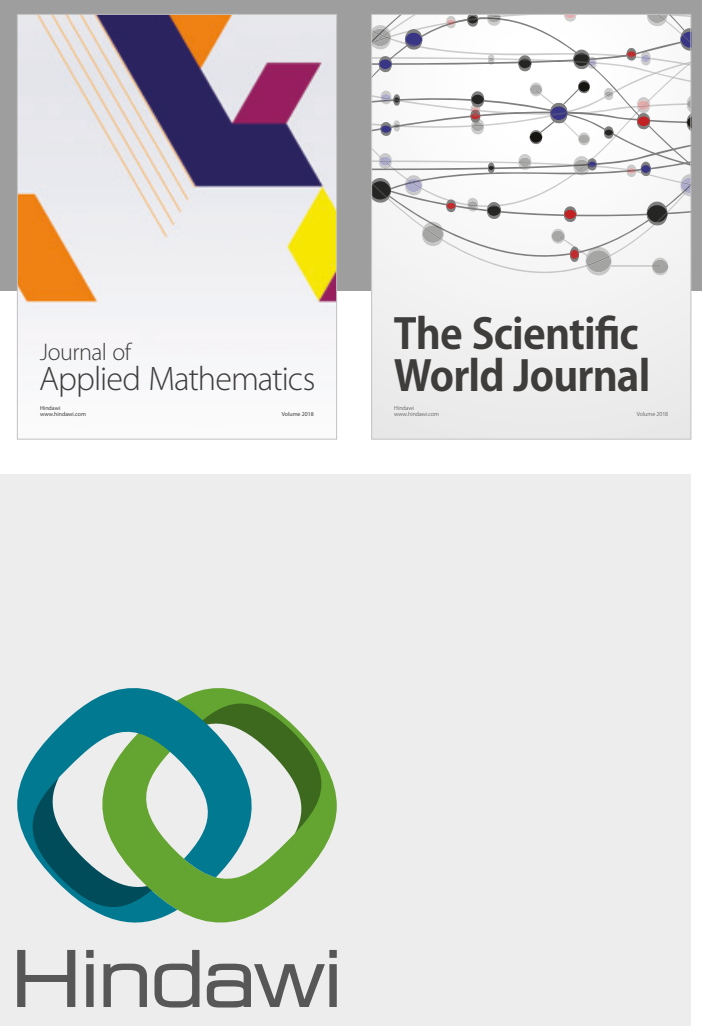

Submit your manuscripts at

www.hindawi.com

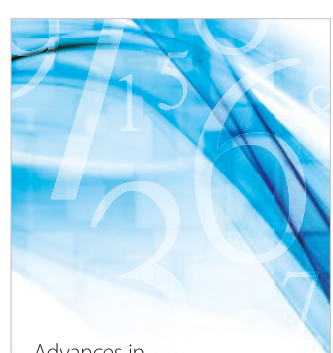

Advances in
Numerical Analysis
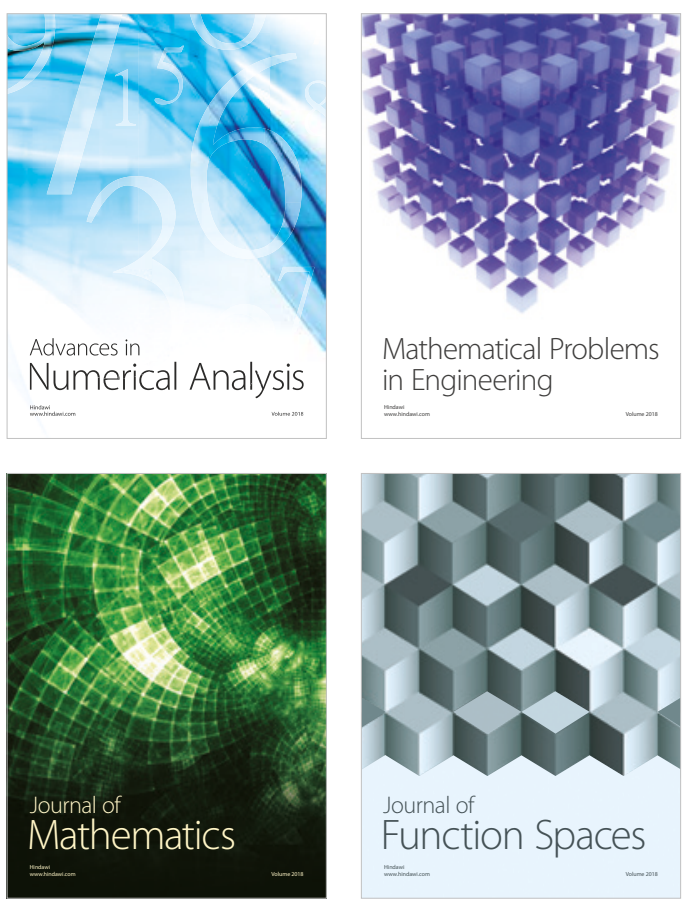

Mathematical Problems in Engineering

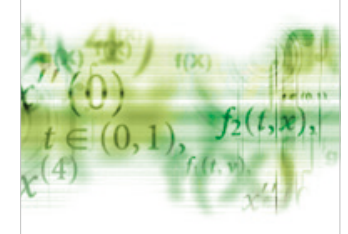

International Journal of

Differential Equations

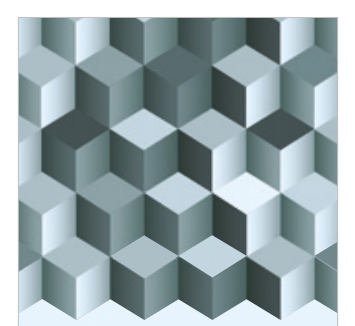

Journal of

Function Spaces

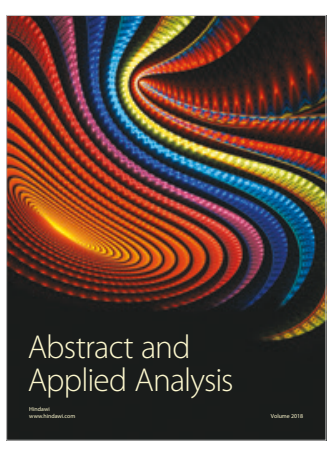

The Scientific

World Journal

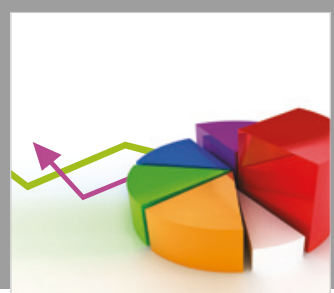

Journal of

Probability and Statistics
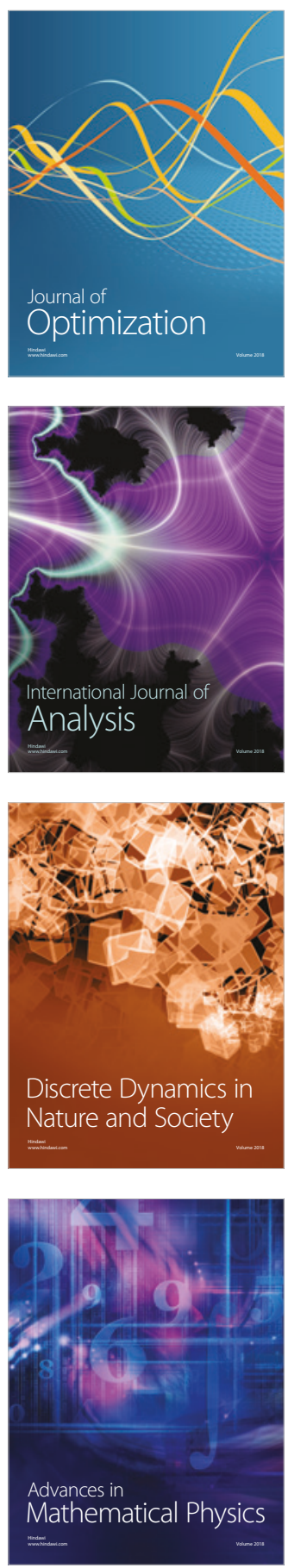